\title{
Association between ABO Genotype and Risk of Hepatocellular Carcinoma in Koreans
}

\author{
Hyung-Jeong Shim ${ }^{1}$, Ran Lee ${ }^{2}$, Min-Ho Shin ${ }^{2,3}$, Hee-Nam Kim³ ${ }^{3}$ Duck Cho ${ }^{4}$, \\ Hye-Ran Ahn ${ }^{5}$, Sun-Seog Kweon ${ }^{2,6 *}$
}

\begin{abstract}
Background: Associations between ABO blood groups and risk of several malignancies have been reported, although there are limited data regarding hepatocellular carcinoma (HCC). The aim of this study was to investigate any possible association between the $\mathrm{ABO}$ genotype, especially blood group $\mathrm{A}$, and $\mathrm{HCC}$ risk in Koreans. Materials and Methods: We conducted a case-control study of 1,538 patients with newly diagnosed HCC at Chonnam National University Hwasun Hospital and 1,305 randomly selected members of the general population. The ABO genotype was determined by multicolor real-time polymerase chain reaction (PCR) using displacing probes. Adjusted odds ratios (aORs) and their 95\% confidence intervals (CIs) were calculated using logistic regression models with adjustment for gender, age, smoking, alcohol drinking, and hepatitis B and C status. Results: The risk of $\mathrm{HCC}$ in genotype AA was significantly higher than in OO (aOR=1.773,95\% $\mathrm{CI}=1.161-2.705)$. The risk in blood group $\mathrm{A}$ was also higher than in blood group $\mathrm{O}(\mathrm{aOR}=1.448,95 \% \mathrm{CI}=1.005$ 1.897). No significant difference was found for the $A A, B O, B B$, and $A B$ genotypes, or blood group $B$ and $A B$. Conclusions: Blood group A and genotype AA showed the highest risks of HCC in a Korean population. No significant difference was found for the $\mathrm{AO}, \mathrm{BO}, \mathrm{BB}$, and $\mathrm{AB}$ genotypes, or blood group $\mathrm{B}$ and $\mathrm{AB}$.
\end{abstract}

Keywords: ABO blood group - ABO genotype - hepatocellular carcinoma - case-control study

Asian Pac J Cancer Prev, 16 (7), 2771-2775

\section{Introduction}

Worldwide, hepatocellular carcinoma (HCC) is the sixth most common tumor and the third leading cause of cancer-related deaths, particularly in Africa, China, Korea, and other Asian nations (Parkin et al., 2005). From the GLOBOCAN 2008 estimates, there were more than 748,000 new cases of liver cancer annually (Ferlay et al., 2010). The age-standard incidence rates, adjusted for WHO populations, of liver cancer in 2010 were 47.3 and 16.5 per 100,000 , males and females, respectively. HCC still ranks as the second most common cause of death from cancer in Korea (Chang et al., 2014).

Major risk factors of $\mathrm{HCC}$ are hepatitis B virus (HBV) infection, hepatitis $\mathrm{C}$ virus (HCV) infection, and alcoholic cirrhosis. (Yeo et al., 2013) Moreover, dietary aflatoxin exposure and cigarette smoking are also associated with the risk of HCC (Humans., 2004). Associations between ABO blood groups and the risk of several malignancies have been reported, including pancreatic cancer (Engin et al., 2012; Woo et al., 2013 gastric cancer (Song et al., 2013; Zhang et al., 2014), epithelial ovarian cancer (Gates et al.,
2011; Poole et al., 2012) and skin cancer (Xie et al., 2010; Cihan et al., 2013), though, there are few reports regarding HCC (Li et al., 2012). A genome-wide association study (GWAS) suggested that ABO blood group antigens may affect systemic inflammation (Melzer et al., 2008; Pare et al., 2008). Because HBV and HCV are the most important causative inflammatory processes in $\mathrm{HCC}$, we suggest that there may be a relationship between $\mathrm{HCC}$ and $\mathrm{ABO}$ blood group. Recently, a Chinese study reported that blood group A showed a higher risk of HCC than other blood groups among chronic hepatitis B patients (Li et al., 2012). Thus, we investigated the possible association between $\mathrm{ABO}$ genotype, especially blood group A, and HCC risk in a Korean population.

\section{Materials and Methods}

\section{Study population and clinical examinations}

The study participants consisted of 1,538 patients with newly diagnosed HCC at Chonnam National University Hwasun Hospital, Korea, between November 2005 and January 2013. The control group $(\mathrm{n}=1,305)$ consisted

${ }^{1}$ Department of Hematology-Oncology, ${ }^{6}$ Jeonnam Regional Cancer Center, Chonnam National University Hwasun Hospital, Hwasun, ${ }^{2}$ Department of Preventive Medicine, Chonnam National University Medical School, ${ }^{3}$ Center for Creative Biomedical Scientists, Chonnam National University, Gwangju, ${ }^{4}$ Department of Laboratory Medicine and Genetics, Samsung Medical Center, Sungkyunkwan University School of Medicine, ${ }^{5}$ Department of Nursing, Nambu University, Gwangju, Korea * For correspondence: ujingogo@paran.com 
of random selected community residents of Jindo-gun and Boseong-gun, Jeollanam-do Province, Korea, who participated in a National Community Survey, administered by the Korean Centers for Disease Prevention and Control (KCDC) in 2012. (Kim et al., 2012) In total, 538 males and 768 females, aged 20 years and older, participated in serological examinations for viral hepatitis and a questionnaire survey (response rate $=75.5 \%$ ). All study subjects provided their informed consent to participate in this study. This study was approved by the Institutional Review Board of the Chonnam National University Hwasun Hospital in Hwasun, Korea.

HCV seropositivity was defined as a positive serum anti-HCV antibody result (HCVAb; sample rate/cut-off rate ratio $>1.0$ ), and $\mathrm{HBV}$ seropositive as the presence of hepatitis B surface antigen (HBsAg) or antibodies against HBV core antigens (anti-HBc). The ARCHITECT chemiluminescent microparticle immunoassays (CMIA) were conducted with Abbott Laboratories (Abbott Park, IL, USA) at Chonnam National University Hwasun Hospital. The study was approved by Chonnam NationalUniversity Hwasun Hospital insIRB

\section{Genotyping}

Details of the genotyping were described in previous reports (Song et al., 2011; 2013). Briefly, genomic DNA was extracted from peripheral blood using a QIAamp DNA Blood Mini Kit (Qiagen, Valencia, CA, USA), according to the manufacturer's protocol. The ABO genotype was determined by multicolor real-time polymerase chain reaction (PCR) using displacing probes. The primers and probes were designed as described by Ruan et al. (2010) and were synthesized and high-performance liquid chromatography (HPLC)-purified by Bioneer (Daejeon, Korea). The reaction mixture included $400 \mathrm{nM}$ PCR primers for exon 6, $500 \mathrm{nM}$ PCR primers for exon 7, 50 $\mathrm{nM}$ probes for $\mathrm{A}$ del and $\mathrm{O}$ del, $100 \mathrm{nM}$ probes for $\mathrm{A}$ and B, 0.5 U f-Taq polymerase (Solgent, Daejeon, Korea), and 40 ng genomic DNA in $25-\mu \mathrm{L}$ reaction volumes. Realtime PCR was performed on a Rotor-Gene 3000 (Corbett Research, Mortlake, Australia). The cycling conditions started with denaturation at $96^{\circ}$ for $2 \mathrm{~min}$, followed by 10 cycles of touchdown PCR $\left(96^{\circ} \mathrm{C}\right.$ for $15 \mathrm{~s}, 68^{\circ} \mathrm{C}$ with $1^{\circ} \mathrm{C} /$ cycle decrease for $20 \mathrm{~s}$, then $72^{\circ} \mathrm{C}$ for $15 \mathrm{~s}$ ) and 40 cycles of $95^{\circ} \mathrm{C}$ for $15 \mathrm{~s}, 58^{\circ} \mathrm{C}$ for $15 \mathrm{~s}$, and $72^{\circ} \mathrm{C}$ for $15 \mathrm{~s}$. Fluorescence from all four channels (FAM, JOE, ROX, and Cy5) was recorded at the annealing step of $58^{\circ} \mathrm{C}$ during the latter 40 cycles.

\section{Statistical analysis}

Regular alcohol drinking was defined as alcoholic drinks more than twice per month and as coding as an alcohol drinker in their medical records, for controls and HCC cases, respectively. Subjects were classified with two groups, HBV and non-HBV, according to current HBV seropositivity and past hepatitis B history. Two other groups, HCV and non HCV, were classified by current HCV seropositivity and past hepatitis $\mathrm{C}$ history. A $\chi 2$ test was used to evaluate differences in categorical variables in subject demographic characteristics. HCC cases and controls differed with respect to age, gender, alcohol drinking, and smoking. Thus, we adjusted for age, gender, and alcohol drinking, stratified in the subsequent multivariable logistic regression analysis. Adjusted odds ratios (aORs) and their 95\% confidence intervals (CIs) were calculated using logistic regression models, with adjustments for gender, age, smoking, and alcohol status, to estimate the association between individual and combined genotypes and HCC. ABO phenotype $\mathrm{O}$ and $\mathrm{ABO}$ genotype $\mathrm{OO}$ were considered reference groups. Interactions of genotype with gender, age, smoking, and alcohol use were estimated using the logistic regression model. We also examined the association of ABO blood group and HCC risk in a model stratified by hepatitis B and $C$ status. Statistical analyses were performed using the SPSS software (ver. 21; Chicago, IL, USA). Bonferronicorrected $\mathrm{P}$ values were also calculated for each analysis to determine statistical significance.

\section{Results}

The characteristics of the 1,538 cases and 1,305 controls are summarized in Table 1 . HCC cases were likely to be younger, males, regular drinkers, current smokers, $\mathrm{HBsAg}$ or HCVAb carriers, and to have previously had liver cirrhosis, compared with controls. The HBsAg and HCVAb positive rates in HCC cases (55.8 and 15.7\%) were higher than those of the controls (3.9 and 2.3\%; Table 1).

Table 2 shows the HCC risk according to ABO blood genotype. The risk of HCC in genotype AA was significantly higher than in genotype $\mathrm{OO}(\mathrm{aOR}=1.773$,

Table 1. General Characteristics of Study Subjects

\begin{tabular}{|c|c|c|c|}
\hline Variables & Cases & Controls & p-value \\
\hline Number & 1,538 & 1,305 & \\
\hline \multicolumn{4}{|l|}{ Age (years) } \\
\hline$<60$ & $661(42.9)$ & $563(43.1)$ & \multirow[t]{2}{*}{$<0.001$} \\
\hline$\geq 60$ & $877(57.1)$ & $742(56.9)$ & \\
\hline \multicolumn{4}{|l|}{ Gender } \\
\hline Men & $1,267(82.4)$ & $537(41.1)$ & \multirow[t]{2}{*}{$<0.001$} \\
\hline Women & $271(17.6)$ & $768(58.9)$ & \\
\hline \multicolumn{4}{|c|}{ Regular drinking* } \\
\hline Yes & $473(30.8)$ & $322(24.7)$ & \multirow[t]{3}{*}{$<0.001$} \\
\hline No & $1,025(66.6)$ & $981(75.2)$ & \\
\hline Unknown & $40(2.6)$ & $2(0.2)$ & \\
\hline \multicolumn{4}{|c|}{ Smoking status } \\
\hline Current & $423(27.5)$ & $233(17.9)$ & \multirow[t]{4}{*}{$<0.001$} \\
\hline Ex & $131(8.5)$ & $183(14.0)$ & \\
\hline Never & $938(61.0)$ & $889(68.1)$ & \\
\hline Unknown & $46(3.0)$ & 0 & \\
\hline \multicolumn{4}{|l|}{ HBs Ag } \\
\hline Positive & $1,026(66.7)$ & $176(13.5)$ & \multirow[t]{3}{*}{$<0.001$} \\
\hline Negative & $498(32.4)$ & $1,129(86.5)$ & \\
\hline Unknown & $14(0.9)$ & $0(0.0)$ & \\
\hline \multicolumn{4}{|l|}{$\mathrm{HCV} \mathrm{Ab}$} \\
\hline Positive & $258(16.8)$ & $32(2.5)$ & \multirow[t]{3}{*}{$<0.001$} \\
\hline Negative & $1,239(80.6)$ & $1,273(97.5)$ & \\
\hline Unknown & $41(2.7)$ & $0(0.0)$ & \\
\hline \multicolumn{4}{|c|}{ Liver cirrhosis history } \\
\hline Yes & $1,188(77.2)$ & $2(0.2)$ & \multirow[t]{3}{*}{$<0.001$} \\
\hline No & $327(21.3)$ & $1,303(99.8)$ & \\
\hline Unknown & $23(1.5)$ & $0(0.0)$ & \\
\hline
\end{tabular}

*Regular drinking defined as drinking more than twice per month 
Association between ABO Genotype and Risk of Hepatocellular Carcinoma in Koreans

Table 2. Hepatocellular Carcinoma Risk According to ABO-blood Genotype

\begin{tabular}{|c|c|c|c|c|c|c|c|}
\hline & & $\begin{array}{c}\text { Cases } \\
(\mathrm{n}=1,538)\end{array}$ & $\begin{array}{l}\text { Control } \\
(\mathrm{n}=1,305)\end{array}$ & $\mathrm{cOR}$ & $\mathrm{p}$-value** & $\mathrm{aOR} *$ & p-value** \\
\hline \multirow[t]{6}{*}{ Genotype } & $\mathrm{OO}$ & $368(23.9)$ & $367(28.1)$ & 1 (Reference) & 0.947 & 1 (Reference) & 0.255 \\
\hline & $\mathrm{AO}$ & $465(30.2)$ & $369(28.3)$ & $1.257(1.030-1.533)$ & 0.381 & $1.369(1.030-1.820)$ & 0.153 \\
\hline & AA & $131 \quad(8.5)$ & 97 (7.4) & $1.347(0.998-1.818)$ & 0.836 & $1.773(1.161-2.705)$ & 0.040 \\
\hline & $\mathrm{BO}$ & $311(20.2)$ & $268(20.5)$ & $1.157(0.930-1.439)$ & 0.618 & $1.306(0.953-1.791)$ & 0.486 \\
\hline & BB & $73 \quad(4.7)$ & $54 \quad(4.1)$ & $1.348(0.922-1.972)$ & 0.122 & $1.608(0.913-2.162)$ & 0.398 \\
\hline & $\mathrm{AB}$ & $190(12.4)$ & $150(11.5)$ & $1.263(0.976-1.636)$ & 0.258 & $1.315(0.909-1.903)$ & 0.731 \\
\hline \multirow[t]{4}{*}{ Blood group } & $\mathrm{O}$ & $368(23.9)$ & $367(28.1)$ & 1 (Reference) & 0.215 & 1 (Reference) & 0.163 \\
\hline & A & $596(38.8)$ & $466(35.7)$ & $1.275(1.056-1.540)$ & 0.034 & $1.448(1.005-1.897)$ & 0.022 \\
\hline & B & $384(25.0)$ & $322(24.7)$ & $1.189(0.967-1.463)$ & 0.302 & $1.358(1.008-1.831)$ & 0.133 \\
\hline & $\mathrm{AB}$ & $190(12.4)$ & $150(11.5)$ & $1.263(0.976-1.636)$ & 0.229 & $1.315(0.909-1.902)$ & 0.440 \\
\hline
\end{tabular}

*Adjusted for age, gender, regular alcohol drinking, smoking status, and presence of hepatitis B or hepatitis $\mathrm{C}$; **Bonferroni-corrected $\mathrm{P}$-values for multiple comparison

Table 3. Association between Blood Group A, Genotype AO/AA, and Hepatocellular Carcinoma Risk According to the Btatus of Hepatitis $B$ and $C$

\begin{tabular}{llccr}
\hline & aOR* & $\begin{array}{c}\text { Total } \\
(\mathrm{n}=1,538 / 1,305)\end{array}$ & $\begin{array}{c}\text { Both negative } \\
(\mathrm{n}=1,108 / 307)\end{array}$ & $\begin{array}{c}\text { HBV }(+) \text { or HCV }(+) \\
(\mathrm{n}=197 / 1,189)\end{array}$ \\
\hline Genotype & AO $v s$ OO & $1.367(1.029-1.816)$ & $1.420(0.949-2.124)$ & $1.176(0.765-1.807)$ \\
& AA $v$ OO & $1.740(1.140-2.655)$ & $1.811(0.995-3.296)$ & $1.435(0.748-2.753)$ \\
& AO $v s$ non-AO/AA & $1.149(0.910-1.451)$ & $1.207(0.875-1.666)$ & $0.996(0.694-1.430)$ \\
& AA $v$ non- AO/AA & $1.479(1.003-2.180)$ & $1.552(0.910-2.650)$ & $1.242(0.674-2.286)$ \\
Blood type & A $v s$ O & $1.447(1.103-1.897)$ & $1.494(1.014-2.202)$ & $1.229(0.817-1.849)$ \\
& A $v s$ non-A & $1.214(0.979-1.507)$ & $1.269(0.940-1.714)$ & $1.046(0.748-1.463)$ \\
\hline
\end{tabular}

*Adjusted for age, gender, regular alcohol drinking, smoking status, and presence of hepatitis B or hepatitis C

95\% CI 1.1612 .705$)$. The risk of HCC in blood group A was higher than in blood group $\mathrm{O}(\mathrm{aOR}=1.448,95 \%$ $\mathrm{CI}=1.005$ 1.897). No significant difference was found in genotypes $\mathrm{AA}, \mathrm{BO}, \mathrm{BB}$, or $\mathrm{AB}$, or in blood groups $\mathrm{B}$ and $\mathrm{AB}$, compared with genotype $\mathrm{OO}$ and blood group $\mathrm{O}$, respectively (Table 2).

The associations between blood group A, genotype AO or AA, and HCC risk according to HBV and HCV status are presented in Table 3. The risk of HCC in genotypes $\mathrm{AO}$ and AA was significantly higher than in genotype $\mathrm{OO}(\mathrm{aOR}=1.367,95 \% \mathrm{CI}=1.0291 .816$, and $\mathrm{aOR}=1.740$, $95 \% \mathrm{CI}=1.140$ 2.655, respectively). The risk of HCC was increased in the subjects with AA $(\mathrm{aOR}=1.479,95 \%$ $\mathrm{CI}=1.103$ 1.897) but not in the subjects with $\mathrm{AO}$, compared with genotype non-AO/AA. No significant difference was found between blood group A and blood group non-A. When stratified by hepatitis B and C status, a significant association between blood group A and $\mathrm{HCC}$ risk was seen only among the hepatitis-free subjects ( $\mathrm{aOR}=1.494,95 \%$ $\mathrm{CI}=1.0142 .202$ ). No significant association was found in the subjects with HBV or HCV seropositive status. These results suggest that the association between $\mathrm{ABO}$ genotype and risk of HCC differs according to hepatitis status.

\section{Discussion}

In this case-control study, the possible association between $\mathrm{ABO}$ genotype and $\mathrm{HCC}$ risk was evaluated in a Korean population. To our knowledge, this is the first study to investigate the relationship between ABO genotype and HCC using community-based cancer-free controls, including non-hepatitis individuals. This study showed that ABO blood type was associated with the
HCC and blood type A; genotype AA increased the risk of HCC, especially in hepatitis-free subjects. The possible association between HCC and blood group A was first reported in a Chinese case-control study, which involved 6,275 chronic hepatitis B (CHB) patients including 1,105 HCC incident cases ( $\mathrm{Li}$ et al., 2012). Among the CHB patients, the risk of HCC was increased in subjects with blood group $\mathrm{A}(\mathrm{aOR}=1.448,95 \% \mathrm{CI}=1.0051 .897)$, compared with blood group $\mathrm{O}$. This finding was consistent with our results. It was hypothesized that blood group A might provide additional risk of $\mathrm{HCC}$ development in the presence of CHB. However, this Chinese study had limited generalizability because the study subjects were confined to $\mathrm{CHB}$ patients with no history of $\mathrm{HCV}$ or alcohol consumption, although both also play important roles in HCC carcinogenesis.

Our findings may provide additional information that blood group A has an increased risk of HCC in the general population after adjusting for several potential confounders, such as age, gender, alcohol consumption, smoking status, and the status of hepatitis. An association between $\mathrm{ABO}$ blood group and some malignant cancers has been suggested in several studies, including a metaanalysis (Zhang et al., 2014). Blood group A increases the risk of cancer, including stomach (Song et al., 2013), ovarian (Poole et al., 2012), and pancreatic (Wang et al., 2012) cancer, and non-O blood groups increase the risk of renal cell cancer (Joh et al., 2012), colorectal cancer (Urun et al., 2012), and skin cancer (Xie et al., 2010). In addition, the exact mechanism(s) by which genetic variants in the $\mathrm{ABO}$ gene locus influence the risk of these various cancers remain (s) unknown. However, evidence on the association between $\mathrm{HCC}$ and $\mathrm{ABO}$ blood groups is lacking. 
The possibility of an association between $\mathrm{ABO}$ blood group and the risk of HCC may be explained by the following. First, blood antigens are known to be important as receptors or ligands for microbes and immunologically important proteins (Melzer et al., 2008; Pare et al., 2008) that are integral to malignant progression and spread (Hakomori, 1999). For HCC, the abnormal expression of $\mathrm{ABO}$ blood antigens in liver tissue might be related to $\mathrm{HCC}$ carcinogenesis. ABO blood antigens $(\mathrm{A}, \mathrm{B}, \mathrm{H})$ are usually expressed on the surface of RBCs and most epithelial tissue but not on hepatocytes in a normal liver. However, increased ABH expression or neo-expression has been observed in HCC tissues (Terada and Nakanuma, 1991). Thus, ABO antigens or ABO antigen expression might have implications for carcinogenesis, including in HCC. Second, it has been reported that non-O blood group is an independent risk factor for the progression of liver fibrosis in HCV infection (Poujol-Robert et al., 2006). When compared with blood group O, subjects with blood group A tend to have more severely impaired liver function and earlier onset of cirrhosis (Li et al., 2012). This suggests an association between ABO blood groups and liver inflammation and fibrosis progression in patients with CHB. Recently, two genome-wide association studies suggested that $\mathrm{ABO}$ blood group antigens might affect systemic inflammation. In an analysis of 496,032 SNPs among 1,200 participants of the InCHIANTI study (Melzer et al., 2008), two SNPs at the ABO locus were associated with serum levels of tumor necrosis factoralpha, an inflammatory cytokine known to modulate rates of pancreatic ductal cell apoptosis (Garcea et al., 2005). In a second, independent study of 336,108 SNPs in 6,578 female participants in the Women's Health Study (Pare et al., 2008), an SNP at the ABO locus was found to be statistically significantly associated with plasma levels of soluble intercellular adhesion molecule 1 , which is a marker of inflammation associated with the risk of incident diabetes (Meigs et al., 2004) and myocardial infarction (Ridker et al., 1998). These results raise the possibility that blood group antigens may alter the systemic inflammatory response and thus suggest a possible mechanism for the association between blood type and HCC risk because hepatitis is the most important underlying disease in HCC. Fourth, risk sharing between each primary cancer site and anatomically adjacent organs is also useful regarding the potential mechanism. An association between blood group A, HBV infection, and extrahepatic cholangiocarcinoma (ECC) risk was reported, with synergism between blood group A and HBV infection in the development of ECC (Zhou et al., 2013).

A unique finding from our study was that the risk of HCC in blood group A and genotype AA was significantly higher than in blood group $\mathrm{O}$, especially in hepatitis-free subjects. In contrast with previous findings from a Chinese study (Li et al., 2012), our findings can be generalized to populations and are also applicable to hepatitis-free individuals. In our study, no statistically significant association was observed for the hepatitis patients, but blood group A showed a higher risk of HCC in hepatitisfree subjects. This discrepancy between our study and the previous Chinese one (Li et al., 2012) suggests that non- inflammatory processes are also related to the association between ABO blood group and risk of HCC. A possible reason for the non-significance in hepatitis subject is that minor risk factors for $\mathrm{HCC}$, such as $\mathrm{ABO}$ blood type, may be diluted by some more dominant risk factor, such as hepatitis.

This study had some limitations. First, it was not a matched case-control study, but used randomly selected population-based controls. Thus, the distributions of demographic and epidemiologic factors, including age, gender, drinking, and smoking, differed between HCC cases and controls. However, the respective $\mathrm{ABO}$ genotype frequencies of $\mathrm{O}, \mathrm{A}, \mathrm{B}$, and $\mathrm{AB}$ in controls, $28.1 \%$, $35.7 \%, 24.7 \%$, and $11.5 \%$, respectively, were consistent with those of previous population-based controls (Song et al., 2013). Second, residual confounding might affect the main results because not all potential confounders, such as family history or alcohol cirrhosis, could be adjusted for in this study. Third, although this study had a relatively large sample size, the numbers of subjects in the subgroup analyses were small. The non-significant findings in hepatitis subjects might due to insufficient statistical power because control subjects with hepatitis $\mathrm{B}$ or $\mathrm{C}$ comprised $<5 \%$ of the total.

In conclusion, blood group A and genotype AA showed the highest risk of HCC in a Korean population. The biological reason for this remains unclear, although this study provides additional insights into HCC carcinogenesis.

\section{Acknowledgements}

This study was supported by grants from the National R\&D Program for Cancer Control, Ministry for Health, Welfare and Family affairs, Republic of Korea (0720570), and from Chonnam National University Hwasun Hospital Research Institute of Clinical Medicine (HCRI 14010-1).

\section{References}

Chang UK, Kim MS, Han CJ, et al (2014). Clinical result of stereotactic radiosurgery for spinal metastasis from hepatocellular carcinoma: comparison with conventional radiation therapy. $J$ Neurooncol, 119, 141-8.

Cihan YB, Baykan H, Kavuncuoglu E, et al (2013). Relationships between skin cancers and blood groups--link between nonmelanomas and $\mathrm{ABO} / \mathrm{Rh}$ factors. Asian Pac J Cancer Prev, 14, 4199-203.

Engin H, Bilir C, Ustun H, et al (2012). ABO blood group and risk of pancreatic cancer in a Turkish population in Western Blacksea region. Asian Pac J Cancer Prev, 13, 131-3.

Ferlay J, Shin HR, Bray F, et al (2010). Estimates of worldwide burden of cancer in 2008: GLOBOCAN 2008. Int J Cancer, 127, 2893-917.

Garcea G, Dennison AR, Steward WP, et al (2005). Role of inflammation in pancreatic carcinogenesis and the implications for future therapy. Pancreatology, 5, 514-29.

Gates MA, Wolpin BM, Cramer DW, et al (2011). ABO blood group and incidence of epithelial ovarian cancer. Int $J$ Cancer, 128, 482-6.

Hakomori S (1999). Antigen structure and genetic basis of histo-blood groups A, B and O: their changes associated with human cancer. Biochim Biophys Acta, 1473, 247-66. 
Humans. IWGotEoCRt (2004). Tobacco smoke and involuntary smoking. IARC Monogr Eval Carcinog Risks Hum, 83, $1-1438$.

Joh HK, Cho E, Choueiri TK (2012). ABO blood group and risk of renal cell cancer. Cancer Epidemiol, 36, 528-32.

Kim YT, Choi BY, Lee KO, et al (2012). Overview of Korean Community Health Survey. J Korean Med Sci, 55, 74-83.

$\mathrm{Li} \mathrm{Q}, \mathrm{Yu} \mathrm{CH}, \mathrm{Yu} \mathrm{JH}$, et al (2012). ABO blood group and the risk of hepatocellular carcinoma: a case-control study in patients with chronic hepatitis B. PLoS One, 7, 29928.

Meigs JB, Hu FB, Rifai N, et al (2004). Biomarkers of endothelial dysfunction and risk of type 2 diabetes mellitus. JAMA, 291, 1978-86.

Melzer D, Perry JR, Hernandez D, et al (2008). A genome-wide association study identifies protein quantitative trait loci (pQTLs). PLoS Genet, 4, 1000072.

Pare G, Chasman DI, Kellogg M, et al (2008). Novel association of $\mathrm{ABO}$ histo-blood group antigen with soluble ICAM-1: results of a genome-wide association study of 6,578 women. PLoS Genet, 4, 1000118.

Parkin DM, Bray F, Ferlay J, et al (2005). Global cancer statistics, 2002. CA Cancer J Clin, 55, 74-108.

Poole EM, Gates MA, High BA, et al (2012). ABO blood group and risk of epithelial ovarian cancer within the Ovarian Cancer Association Consortium. Cancer Causes Control, 23, 1805-10.

Poujol-Robert A, Boelle PY, Wendum D, et al (2006). Association between $\mathrm{ABO}$ blood group and fibrosis severity in chronic hepatitis C infection. Dig Dis Sci, 51, 1633-6.

Ridker PM, Hennekens CH, Roitman-Johnson B, et al (1998). Plasma concentration of soluble intercellular adhesion molecule 1 and risks of future myocardial infarction in apparently healthy men. Lancet, 351, 88-92 .

Ruan L, Zhao H, Li Q (2010). Multicolor real-time PCR genotyping of $\mathrm{ABO}$ system using displacing probes. $J$ Forensic Sci, 55, 19-24.

Song HR, Kim HN, Piao JM, et al (2011). Association of a common genetic variant in prostate stem-cell antigen with gastric cancer susceptibility in a Korean population. $\mathrm{Mol}$ Carcinog, 50, 871-5.

Song HR, Shin MH, Kim HN, et al (2013). Sex-specific differences in the association between $\mathrm{ABO}$ genotype and gastric cancer risk in a Korean population. Gastric Cancer, 16, 254-60.

Terada T, Nakanuma Y (1991). Expression of ABH blood group antigens, receptors of Ulex europaeus agglutinin I, and factor VIII-related antigen on sinusoidal endothelial cells in adenomatous hyperplasia in human cirrhotic livers. Hum Pathol, 22, 486-93.

Urun Y, Ozdemir NY, Utkan G, et al (2012). ABO and Rh blood groups and risk of colorectal adenocarcinoma. Asian Pac J Cancer Prev, 13, 6097-100.

Wang DS, Chen DL, Ren C, et al (2012). ABO blood group, hepatitis B viral infection and risk of pancreatic cancer. Int J Cancer, 131, 461-8.

Woo SM, Joo J, Lee WJ, et al (2013). Risk of pancreatic cancer in relation to $\mathrm{ABO}$ blood group and hepatitis $\mathrm{C}$ virus infection in Korea: a case-control study. J Korean Med Sci, 28, 247-51.

Xie J, Qureshi AA, Li Y, et al (2010). ABO blood group and incidence of skin cancer. PLoS One, 5, 11972.

Yeo Y, Gwack J, Kang S, et al (2013). Viral hepatitis and liver cancer in Korea: an epidemiological perspective. Asian Pac J Cancer Prev, 14, 6227-31.

Zhang BL, He N, Huang YB, et al (2014). ABO blood groups and risk of cancer: a systematic review and meta-analysis. Asian Pac J Cancer Prev, 15, 4643-50.

Zhou Y, Zhou Q, Lin Q, et al (2013). Evaluation of risk factors for extrahepatic cholangiocarcinoma: ABO blood group, hepatitis B virus and their synergism. Int J Cancer, 133, 1867-75. 